\title{
The "soft" Dimension of Organizational Knowledge Transfer
}

\author{
Gustavo A C Guzman \\ University of Nottingham, UK \\ Federal University of Minas Gerais, Brazil \\ gustavo.guzman@nottingham.ac.uk \\ John Wilson \\ University of Nottingham, UK \\ j.wilson@nottingham.ac.uk
}

\begin{abstract}
Based on empirical work and literature review, this paper has advanced a theoretical framework that integrates knowledge management, change management and 'soft' issues. It argues that the "soft" dimension helps to better understand the process of organizational knowledge transfer. Guidelines for managerial action were formulated in order to make explicit, be aware and understand embedded 'soft' issues.
\end{abstract}

Keywords. Organizational knowledge, soft issues, knowledge transfer 


\section{INTRODUCTION}

Conventional views of knowledge management focus either on (a) the understanding of the process creation and transfer of organizational knowledge, or (b) the development of practical tools in order effectively to 'manage' organizational knowledge (Tsang, 1997, Easterby-Smith et.al. 2001). While different approaches are useful for different situations, (Edmondson and Moingeon, 1996), there still seems to be a lack of understanding of the roles of different theoretical frameworks. Some views, for example, focus on the micro-organizational, social and cognitive processes in which knowledge is created, transformed and transferred (c.f. Nonaka and Takeuchi, 1995; Argyris and Schon, 1974, Norman, 1988; Baumard, 1999). Other group looks at the organizational level processes, components and developed capabilities that support knowledge acquisition, assimilation and exploitation (c.f. Cohen and Levinthal, 1990; Zahra and George, 2002; Brown and Duguid, 1988; and Senge, 1990). A third group examines the wider national and industry sector paths of knowledge creation and transfer (c.f. Solvell and Zander, 1999; von Hippel, 1988; Nelson, 1993; and Teece, 2001).

Those approaches usually cover micro-, organizational and macro- perspectives independently. The problem is that they are rarely integrated. For example, while focusing on the specific - and complex - mechanisms for promoting conversion and transfer of knowledge, they do not address the crucial point of how the industry sector path of knowledge transfer affects micro organizational and cognitive processes. 
The important question, therefore, is how do we configure the different alternative theories and methods - which focuses on the same problem from different levels of analysis - in order to 'make sense' at a specific context? It is necessary to create an overarching framework that guides practitioners on the manipulation of existing theoretical tools.

The goal of this study is to contribute, from the organizational perspective, towards the understanding of key aspects that shape the transfer of organizational knowledge. Based on a case study and literature review, an architecture for understanding the existing theoretical frameworks is delineated firstly. Secondly, we intend to point out key 'soft' managerial aspects that need to be considered in order to support the transfer process.

The next three sections outline the concept of organizational knowledge, the problems and the 'process' of organizational knowledge transfer. The case study is developed in Section 5, and the theoretical framework is delineated in section 6. The 'soft' dimension is further examined in the following section, and managerial guidelines for coping with 'soft' issues are outlined in section 8.

\section{ORGANIZATIONAL KNOWLEDGE}

Organizational knowledge is a concept with a wide scope. On the one hand, it refers to socially constructed templates (concepts, methods, routines, techniques and tools) usually used to improve performance. JIT, TQM, matrix organizational architectures, 
design for manufacturing (DFM), teamwork, participating practices and performance measurement systems (PMS) and Continuous Improvement, are the most well known.

On the other hand, organizational knowledge is also attached to 'artefacts' (i.e. equipment, machines) or to 'technical processes'. In both cases, organizational knowledge is needed in order to adapt either artefacts or technical processes to the specific - social and technical - local conditions of operation, and/or vice-versa.

Organizational knowledge, therefore, involves both people and context. Its realization depends mainly on people who interpret, organize, plan, develop and execute and use those templates. It also depends on the specific situation, and does not depend on absolute truths or quantitative facts. This means that people's values and assumptions permeate behaviour, decisions and actions related to the transfer of organizational knowledge. Thus, the creation and transfer of organizational knowledge needs to be justified and understood; people need to be persuaded and human cohesion is demanded (Clark, 2003; Krogh et.al., 2000).

The main features of organizational knowledge are (Spender, 1993; Cohen and Bacdayan, 1994; Fruin, 1997; Cohen 1991; Tsoukas and Vladimirou, 2001),

1. It can be partly codified and so independent of the source. 
2. It can be partly tacit (that is, practical) and conscious. For example, people can apply a specific practical knowledge in order to obtain the desired result. In this sense, it is also personal knowledge.

3. It can be partly tacit and automatic. This means that users may be unaware of the tacit knowledge being applied. Its application becomes effortless. It is related to individual skills. It is memory for how things are done that is automatic and inarticulate, and it encompasses cognitive as well as motor activities.

4. It is multi-actor. Organizational knowledge is usually distributed among a group of people. Thus, organisational knowledge is 'collective'.

5. It is tied to a specific context. Because complex organizational capabilities developed over time are to a significant extent tacit and supported by macro, micro and institutional forces (which in turn are also difficult to transfer), organizational knowledge only makes sense when it is directly related to specific situations.

6. It has, partly, a 'process service' nature. That is, it relates to human services (for example, health services) which demand a high degree of tacit knowledge in order to know how to perform specific tasks (Miles, 1994). As Fruin $(1997 ; 162)$ put it: "The nature of factory know-how is not contained in manuals but is found instead in practice and experience".

7. It is emergent. Because organizational knowledge is partly tacit (that is, it is in people's minds), and because people's minds evolve, the application of organizational knowledge cannot be totally planned. 
We can conclude by stating that organizational knowledge is abstract and possesses "soft" features, which are related to subtle, implicit, embedded and invisible knowledge, presumptions, values and ways of thinking which permeate behaviour, decisions and actions. As such, organizational templates are ill-defined, do not have clear boundaries, and they are context-dependent. Outcomes and performance of organizational knowledge are also difficult to specify, understand and measure. Tsoukas and Vladimirou (2001) have clearly captured the multi-faceted concept of organizational knowledge when noting that

“... knowledge is the individual capability to draw distinctions, within a domain of action, based on appreciation of context or theory, or both ... Organizational knowledge is the capability members of an organization have developed to draw distinctions in the processes of carrying out their work, in particular concrete contexts, by enacting sets of generalizations whose application depends on historically evolved collective understandings and experiences". (p.983)

The above set of characteristics of organizational knowledge explains the difficulty for understanding, managing and transferring organizational knowledge. In the next section some key problems are identified.

\section{PROBLEMS FOR TRANSFERRING ORGANIZATIONAL KNOWLEDGE}

The main problems associated with OKT are related to the complexity of the social processes that occur during the transfer process, to structural organizational factors and 
to the degree of abstraction in which organizational knowledge is packaged in order to be transferred.

Organizational knowledge is complex because knowledge transfer is based on individual interpretation, cognition and behavior that in turn can be shaped by contextual rules and resources. In order for knowledge to be transmitted effectively, it must be congruent with the existing social context. And this does not happen easily in situations in which the transfer of knowledge is inter-organizational, let alone in cases of international knowledge transfer (Macharzina et.al., 2000).

The additional 'structural' features that prevents fluid OKT include: the existence of conflicting goals inside (Perrow, 1979) and between organizations (such as, for example, in the case of customer-supplier OKT); the low trust level that might exist among sending and receiving organizational units (Child and Faulkner,1998); the limits of human rationality (March and Simon, 1958); and the limitations of the systemic approach used both to diagnose problems and design solutions (Brown, 1992).

Simultaneously, the degree of abstraction in which organizational knowledge is packaged in order to be transferred is also problematic. On the one hand, in order to minimize transaction costs associated with the transfer of organizational knowledge, 'organizational concepts' and/or 'management tools' are standardized and 'packaged'. Nevertheless, since firms do not have, necessarily, the same production technologies, work organisation, factory layouts, work flow and quality of human resources, the 
'adaptation' process is difficult because it is site-specific. On the other hand, the transfer process depends on the level of abstraction in which 'concepts' to be transferred are 'packaged' (Lillrank, 1995). If organizational concepts are complex, the level of abstraction needs to be high in order to capture the whole idea. The problem is that high abstraction levels imply a higher difficulty that needs to be understood. Therefore, inputs (for example, people, information, raw materials), means (for example, data, information, equipment) and outputs (products, services) are difficult to measure, locate and programme. Conversely, if the level of abstraction is low, while it will be easier to understand, it may be so simplified that it cannot capture important elements of the idea.

In short, because of the above problems, OKT requires 'adaptation' of either the concept being transferred, the recipient's socio-technical features, or both simultaneously (Westney, 1987; Leonard-Barton, 1988).

\section{THE PROCESS OF ORGANIZATIONAL KNOWLEDGE TRANSER}

Roughly, the literature on creation and transfer of organizational knowledge can be grouped in two categories, individual and organizational approaches.

At the individual level, the focus is on the social and cognitive micro-processes in which knowledge is created, transformed and transferred. Nonaka and Takeuchi (1995) posited that the creation and transfer of organizational knowledge occurs through processes of conversion and assimilation, including the conversion from tacit to formal 
(and vice versa) and the transfer from individual to collective (and vice-versa). These processes occur through socialization, externalization, combination and internalization.

Argyris and Schon's (1974) distinction between espoused theory (what an individual believes) and theory-in-practice (that is, what the individual actually does) as well as the concept of double-loop learning (that involves questioning the governing conditions of error detection and correction, as well as its associated values) helps to understand different types of behavior that leads to supportive or constraining learning environments.

Whilst the above concepts represent an advance towards the understanding of the individual-level mechanisms that support or constrain learning processes, its utilization is difficult. Three reasons have been pointed out by the literature (Easterby-Smith and Lyles, 2003; Glisby and Holden, 2003). First, ideas were derived eclectically from a range of sources and sub-disciplines, therefore no single stream of academic discourse is identified with those ideas. Second, there are some concepts that challenge or run counter values and beliefs of the mainstream academic community, such as the emphasis on practice, direct interventions and the reliance on subjective experience. This goes counter to the training and values of management scholars, especially those in the USA since they are trained within the positivist and empirical approaches. Thirdly, Nonaka and Takeuchi's claims of universal validity seem to be constrained because their theoretical propositions rest heavily on a tacit foundation of Japanese values and management practices. The Japanese willingness to exchange knowledge via 
socialization, for example, is dependent not only on the pervasiveness of mutual obligation networks and the high level of interdependence between firms, suppliers, banks and subcontractors, it also depends on the culturally-rooted Japanese style of sharing tacit knowledge, which is founded on strong inter-personal relationships, collegiality, corporate affiliation and employment systems.

At the organizational level, the literature looks at the processes, components and developed capabilities that support knowledge acquisition, assimilation and exploitation. Brown and Duguid (1998) have showed the key role played by collective practitioners which share, via socialization, practical knowledge. Senge's (1990) insights propose practical guidance for intervention. He states that learning can be achieved by creating a shared vision, using systemic thinking, and developing leadership competencies that support empowerment, dialogue, flexibility and the building of shared mental models.

Cohen and Levinthal, (1990) have focused on the firm's 'absorptive capability' to search, acquire and assimilate knowledge. Absorptive capabilities have four dimensions that perform different roles. Acquisition refers to the firm's capability to identify and acquire externally produced knowledge. Assimilation refers to the firm's routines and processes that allow the examination, interpretation and understanding of the information obtained from external sources. Transformation refers to the firm's capability to develop and refine the routines that facilitate 'combination' processes. Exploitation involves routines that allow firms to refine, extend, and leverage existing knowledge by incorporating it into to its operations (Zahra and George, 2002:189-190). 
Examining the organizational literature on the process of knowledge creation and transfer, it is possible to suggest that it is a change process (c.f. Lee and Bennet, 2000; Lullies, 2000). Not surprisingly, mechanisms identified by the literature on OKT converge to a significant extent with the literature on change management. The following mechanisms seem to be crucial (Krogh et. al., 2000; Kotter, 2000; Clegg and Palmer, 1996; McCalman J. and Patton R., 1992; Teece, 2001; Kanter, 1996; Bessant et.al, 2003; Leonard-Barton, 1995; Buchanan and Badham, 1999; Brown and Duguid, 2001):

> Install a vision of knowledge, in order to legitimize knowledge generation and diffusion inside the firm;

$>$ Manage 'politics', in order to minimize fear and trust barriers. Since change and learning is people-dependent, power and politics may play an important role;

> Mobilize knowledge/change agents, that is, activate people who coordinate processes to create and diffuse knowledge;

Build organizational structures aligned with both strategy and external context, as well as being based on principles of redundancy and overlapping business processes;

$>$ Disseminate knowledge through all organizational levels;

> Solving operational problems by drawing upon cross-functional expertise;

Implementing and integrating new tools and technologies;

$>$ Developing higher levels of experimentation; and 
Importing knowledge from outside the company

While the organizational level literature has developed more practical-oriented concepts, still their implementation is far from simple. Three reasons explain this. Firstly, while mechanisms to support the creation of communities-of-practice and develop learning-oriented leadership have been pointed out, still it is not clear in which situations mechanisms are appropriate, because of the context-dependent feature associated to OKT. Second, whilst the concept of absorptive capabilities rightly systematizes a series of factors associated with OKT, it mainly focuses on setting the adequate 'inputs' in order to obtain the desired 'outputs', overlooking how the micro cognitive and organizational processes supporting OKT are developed. Thirdly, while the above list of 'supporting' factors may help to guide OKT processes, still it is too rough to apply. For example, how may we 'disseminate' knowledge across all organizational levels?

We can conclude this section by affirming that there is a lack of understanding of the roles of different theoretical frameworks. That is, having a specific OKT situation, how do we configure the different alternative theories and methods available in order to 'make sense' at a specific context? It is necessary to have an overarching framework that guides practitioners on the manipulation of existing theoretical tools. Based on a case study, in the next sections an architecture for understanding the existing theoretical frameworks is delineated. 


\section{CASE STUDY: THE TRANSFER OF 'CONTINUOUS IMPROVEMENT' AT AN ELECTRONICS CONTRACT MANUFACTURING PLANT}

Elsewhere (Guzman and Wilson, 2003) we have studied the implementation process of the concept of Continuous Improvement $(\mathrm{Cl})$ at an Electronic Contract Manufacturing plant in Brazil, from the perspective of OKT.

$\mathrm{Cl}$ was defined as having a high level of abstraction, not only because it is associated with both "soft" and macro related factors governing its application, but also because the concept has little stability and high ambiguity. Firstly, $\mathrm{Cl}$ is an umbrella label that encompasses different organizational techniques, in order to improve operational processes. The problem is that those techniques do not incorporate non-technical ("soft") aspects that seem to be crucial in explaining satisfactory operational results (Guzman, 2003). Secondly, the concept of Cl was derived from Japanese kaizen, which demands the existence of macro institutions to support firm level cooperation, will and commitment (Fruin, 1992; Cole, 1989). Thirdly, rather than a unique $\mathrm{Cl}$ model, there is a myriad range of $\mathrm{Cl}$ models which can be applied under different shopfloor practices. This leads to increasing ambiguity regarding both interpretation of information and applicability (that is, matching production philosophies of sender and receiver units) (Steenhuis and Bruij, 2001).

Results indicated that while 'satisfactory' operational results were achieved, they would have been much better had the implementation of the $\mathrm{Cl}$ process been approached as a 
process of OKT. Explanations seem to be associated with 'other' factors rather than to 'common' implementation errors.

First, there was a lack of awareness (a "soft" issue) regarding the influence of macro factors on firm level performance. On the one hand, the general high 'power distance' and conservative management thinking existing in Brazil helps to explain the generallyaccepted assumption that personnel were paid to do their duties and $\mathrm{Cl}$ was simply part of them. There was neither a professional career path nor promotions because there was little revenue growth. The use of temporary workers introduced further apprehension on the shopfloor, since their number was a function of (unstable) demand. On the other hand, low individualism, good communication skills and predominant informal social relations explain the - at least, short term - enthusiasm and commitment shown in the first stage of the project.

Additional explanations were found outside the firm. Both regional (low) wages and the uneven national income distribution further explain the low level of commitment and motivation to pursue the $\mathrm{Cl}$ project. The particular features of regional labour markets that allowed the recruitment of qualified personnel without raising wages simultaneously constrained organizational knowledge accumulation.

Secondly, the contractual relationship between the external consultants and the plant was another "soft" issue that influenced outcomes. Despite $\mathrm{Cl}$ being an intangible concept with a high degree of abstraction, the factory demanded that the proposal for 
the $\mathrm{Cl}$ project had clearly specified phases and a timetable, something which is extremely difficult given the "soft" nature of $\mathrm{Cl}$ as a concept. Additionally, there was pressure to minimise the total length of the project in order to minimize costs. Because delays occurred in the 'development' stage due to the cancellation of several meetings (the $\mathrm{Cl}$ project had a low priority among personnel on the SMT line), the 'development' phase had to be stretched at the cost of the 'implementation' phase. Thus, there was not space for the management of 'unexpected' events such as the cancellation of meetings at the 'development' stage. Therefore, the rigidity of the proposal - resulting from the external consultants-firm relationship - was another "soft" factor that constrained operational achievements.

Thirdly, the $\mathrm{Cl}$ project was divided into 'development' (of the solution) and 'implementation' stages. While the development phase was adequate, the implementation stage was poorly planned, organised and supported. It seems that both the external consultants and the area manager assumed - incorrectly - that after the action plans were handed in and accepted by the team, their implementation would pass off without problems. It was not the case. Neither the external consultants nor the area manager realised that there were two independent phases and that the full development of the $\mathrm{Cl}$ project depended on the right performance in both phases. The 'myopia' of both the external consultants and the area manager to build the necessary organizational and social conditions to support the implementation process is another "soft" factor that helps to explain outcomes. Yet that myopia can also be credited to people's 'bounded rationality' (March and Simon, 1958). 
Drawing from our empirical evidence, it can be suggested that "soft" issues - intangible and therefore difficult to describe, express and related to either unwritten rules or to 'invisible' macro contextual factors - seem to be fundamental to understand the full set of factors that influence the transfer of organizational knowledge. The idea of $\mathrm{Cl}$ was implemented as if it were isolated from macro factors, implementation issues and the creation of an enabling organizational environment. This leads us to infer that the 'implementation' of an organizational template can be better understood - and be successful - if approached as a 'transfer' process of organizational knowledge. Thus, there is a need to understand how "soft" issues combined with change management and knowledge management issues constrained or supported the process of OKT. In the next section, a framework integrating those elements is outlined.

\section{A THEORETICAL FRAMEWORK FOR ORGANIZATIONAL KNOWLEDGE TRANSFER}

Our empirical data has shown that the understanding of processes for creation and transfer of organizational knowledge go beyond the micro (organisational and cognitive) processes to transfer organizational knowledge and its associated change management aspects. It is also related to both micro and macro "soft" issues that surround knowledge management and implementation issues. While the influence of micro institutional factors (for example, values or unwritten rules for promotion) is clear, the extent to which macro institutional factors affect the processes of conversion and transfer are neither direct nor explicit. Rather, macro institutional factors (for example, 
low regional wages) rooted in the general industrial culture seem to be difficult to be perceived by practitioners; even if perceived, they usually go beyond their scope of decision making. Therefore, practitioners are either unable to perceive the role of macro factors or are incompetent to modify them, leaving them to one side or overlooking them. In the case of developing nations like Brazil, for example, macro contextual conditions seem to be more important than micro level factors, since the basic prerequisites for knowledge transfer - such as motivation, collaboration, willingness, trust and reliability — are structurally restricted by adversarial macro conditions.

Building on both the case study and existing theory (Burkink, 2002; Shariq, 1999; Galbraith, 2000; Goh, 2002), new insights are advanced in order to contribute to the understanding of the process of organizational knowledge transfer. An encompassing model, integrating 'soft' issues, change management and knowledge management aspects is proposed. The model possesses three independent dimensions (see Figure 1).

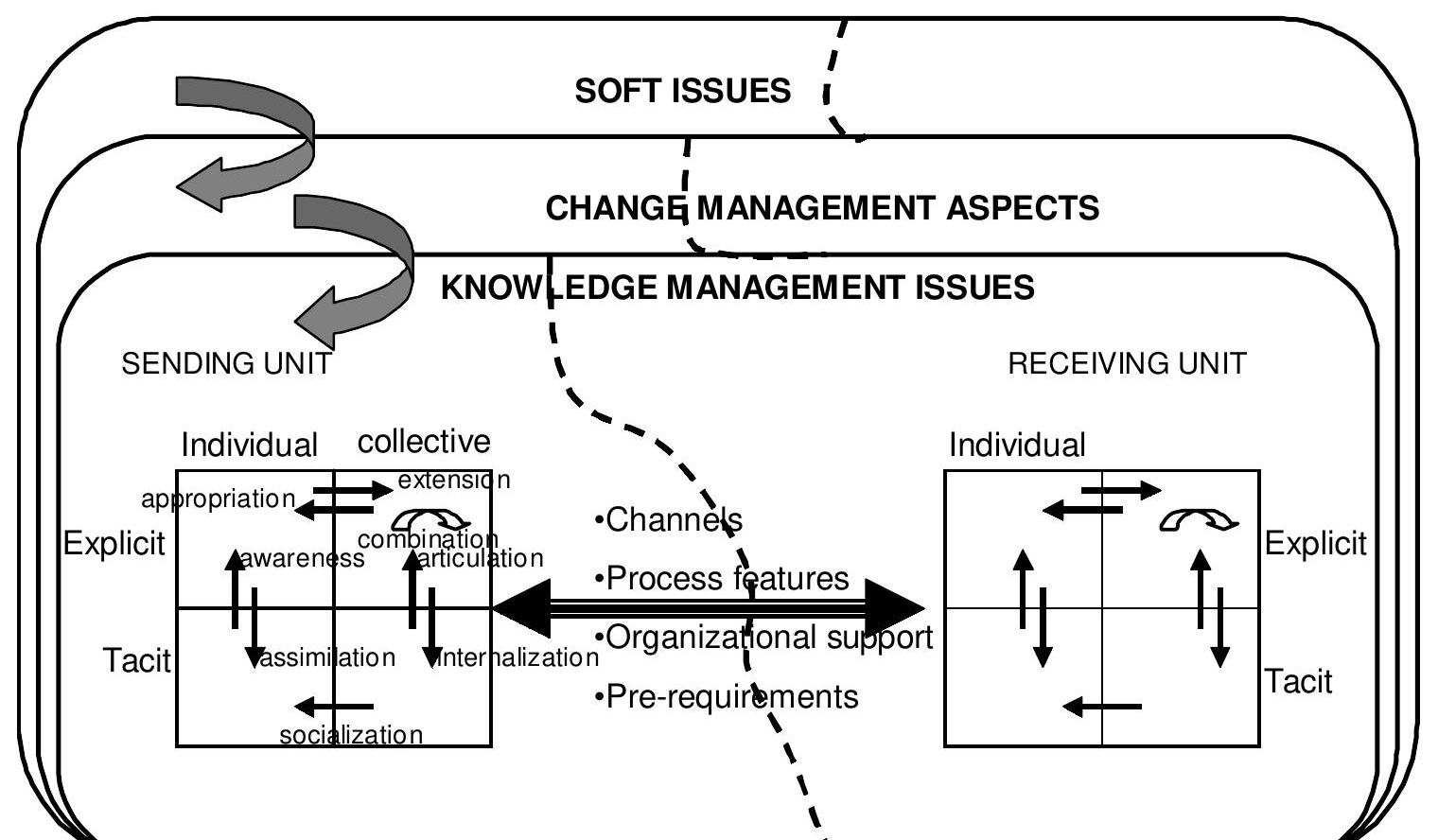


1. The "soft" dimension refers to underlying assumptions, the role of macro institutional factors affecting firm level actions (the macro-micro link) and interpretative aspects that permeate the process of organizational knowledge transfer (c.f. Guzman, 2003). Since those issues are usually overlooked (or even ignored) by the knowledge/learning literature, it is necessary to incorporate "soft" issues into the elaboration of a framework for organizational knowledge transfer. 
Acknowledging the existence and understanding of 'soft' issues seems to be a pre-requisite for adequately handling them.

2. The change management dimension. Because the process of knowledge creation and transfer is a change process (Hendry, 1996; Krebsbach-Gnath, 2000), organizational knowledge transfer therefore requires 'adaptation' of either the concept being transferred, the recipient's socio-technical features, or both simultaneously (Westney, 1987). This dimension involves the application of organizational templates (methods, tools, guidelines) directly related to facilitate the implementation process. Literature on the topic is widely developed (c.f. Collins, 1998; Beer and Nohria, 2000). The decision on what model or approach to follow, however, is far from simple. Awareness of the influence of macro factors on micro level issues, the politics embedded on the selection process and the interpretative aspects surrounding the 'definition' of contextual conditions, seems to be key factors in defining which change approach will be used. The decision on what type of change management template to use is, therefore, a "soft" issue by itself.

3. The Knowledge management dimension focuses on both the individual and organizational level of cognitive and organizational processes that allows knowledge conversion and transfer. This dimension has been the main focus of the literature on knowledge creation and transfer at the cost of ignoring or overlooking "soft" and change process issues. 
Only after acknowledging and addressing both "soft" and change management factors that constrain the transfer process is it convenient to focus on the specific processes involved in knowledge transfer, such as channel (communication frequency, strength of interpersonal relations and communication bi-directionality), process features (temporality, absorption and value of knowledge), organizational support mechanisms (organizational design and organizational processes). The reason for proposing this dynamic is simple. Knowledge conversion and transfer processes demand as crucial prerequisites trust, willingness and motivation between and among sending and receiving personnel. And it seems that addressing both "soft" and change management factors minimizes obstacles for knowledge transfer. In the next section the 'soft' dimension of the process of OKT is further explained.

\section{THE “SOFT” DIMENSION OF ORGANIZATIONAL KNOWLEDGE TRANSFER}

In this model, "soft" issues refers to the mutual understanding - of both sender and receiver units - of underlying assumptions, role of macro institutional factors affecting firm level actions (the macro-micro link) and interpretative aspects that permeate the process of organizational knowledge transfer.

The understanding of "soft" issues becomes of crucial importance in situations in which the degree of shared organizational goals is low, and the environment is both uncertain and ambiguous (Stacey, 1996). In those situations, decisions tend to be intuitive and unprogrammed, and control is normative or based on group pressure. That is, transfer 
of organizational knowledge is more likely to fail "...unless the governing philosophy the system underlying structurational conventions - fits the system of meaning of those expected to implement these procedures from day to day, or unless the organizational routines are transformed so that they conform to existing cultural expectations" (Macharzina et.al., 2000:635-6).

Because of its open-ended nature, it is not possible to explain all "soft" factors that affect OKT. What is possible to point out is the nature of certain "soft" issues which influence key decision/actions that, in turn, affect the process of OKT. We focus on three themes. The first is related to the "soft" process of choosing the appropriate change management template. The second offers insights on the 'soft' concept of 'double loop learning'. The third focus on the 'soft' process of understanding openended situations.

\section{The 'soft' process of choosing the appropriate change management template} Combining Burns and Stalker's (1961) idea of linking degree of environmental uncertainty with type of organizational structures, and Perrow's (1979) insight on the existence of different extents to which organizational goals are shared or agreed, Stacey (1996) has proposed a model that helps to determine what type of organizational rationale and its associated methods are to be used under different conditions. 
- If organizational goals are closely shared among members and if the environment is close to certainty, the use of technically rational decision-making, organizational structure and processes are adequate for monitoring the continuity of operations.

- In the situation in which environment is close to certainty but organizational goals are away from agreement, political processes are the way in which decisionmaking, organizational structure and processes can be adequate. Therefore, compromising, negotiation and the building of dominant coalitions are important.

- In the case of an organization having shared goals but performing in an uncertain environment, decisions and control processes are ideologically driven, based on judgment and control is based on conformity.

- In the case in which exists high uncertainty regarding both shared organizational goals and environment, decisions tend to be intuitive and unprogrammed and control is normative or based on group pressure. Garbage-can models, brainstorming, dialectical inquiry and trial and error methods seem to be adequate in this situation.

From the above brief examination, what seems to be clear is that strategies, decisionmaking and structuring of processes can be intentional and deliberate in conditions of certainty. Nevertheless, there seems to be no alternative but to be emergent in 
conditions of high uncertainty. The latter scenario also is the field in which the creation and transfer of organizational knowledge can better contribute for the firm's performance. While organizational research has mainly focussed on the first three scenarios, the understanding of the latter seems to be key for developing supportive organizational knowledge structures, processes, control and decision-making activities and mainly for the management of informal - or shadow - systems that work alongside the formal organizational system (Stacey, 1996:48).

\section{Insights on the concept of double loop learning}

Double-loop learning (Argyris and Schon, 1974), or self-transcending knowledge, (Scharman, 2001) occurs when people question their own (and shared) mental models; improve contextual assumptions and understand the underlying philosophy of established norms and routines in order to understand the grammar of key decisions, non-decisions, actions, and non-actions. Stacey (1996) pointed out that questioning mental models triggers fears of malfunctioning; destroying established routines as well as embarrassing themselves with questioning that may appear incompetent or threatening. This in turn implies activating automated defence routines that are named as 'covert politics'. Organizational defence routines are patterns of behaviour that people in an organization deploy to protect themselves and others from embarrassment and anxiety. Organizational defence routines can be conscious or unconscious. While conscious routines involve the well known 'political games', unconscious routines refers to actions in which a group of people are engaged without consciously agreeing to it or even realising that they are doing it. Accordingly to Stacey (1996), this means that 
“... when people focus on the contradictions between their mental model representation of the word and their experience of it, they become anxious. That anxiety may rise to such high levels, that people swing into automatic basic assumption behaviour ... However, as soon as open ended-issues present themselves to people in an organization, the level of ambiguity and uncertainty rise dramatically and leaders can no longer deal with the situation by applying their authority. We can think in terms of the level of ambiguity being tuned up while the level of applied power is turned down. These inevitable consequences of the open-ended issues that are so characteristic of strategic management means that the political cognitive and unconscious loops that we previously ignored as background now become very important; they are activated to be come major parts of the process of decision-making and control " (p.401 and 418).

In short, it is suggested that power and politics represent a major factor for complex learning (c.f. Buchanan and Badham, 1999). The use of power is part of a constructive learning process that needs to be considered in the process of OKT.

\section{Understanding open-ended situations}

Although high uncertainty and ambiguity prevails in certain situations, it is still possible to understand - and handle - open-ended situations. Stacey (1996:442) has proposed 
that the understanding of open-ended situations seems to pass through the following stages:

- Discovery, which involves detecting and selecting issues; interpreting and, reflecting upon;

- Choosing, that includes clarifying preferences and problem-solving alternatives; gaining attention and building agenda and; gaining legitimacy and backing;

- Acting, involving taking experimental action and incorporating results into organisational memory.

Each of one of the above stages and its associated components are characterised as "soft" issues since both the understanding of underlying assumptions and implementation pass through interpretation and sense-making of highly uncertain and ambiguous events. Acknowledging its existence and understanding them are prerequirements for adequately handling 'soft' issues that permeate processes of creation and transfer of organizational knowledge. In the next paragraphs, each one of those 'soft' issues is briefly outlined.

\section{Detecting and selecting open-ended issues}

Poorly defined and messy situations constrain the definition of the fundamental nature of the problem. Accordingly McCaskey (1988:2-5) in this situation '... information is incomplete and of dubious reliability; and events are not easily categorized. Contradictions then appear as signposts. They call attention to a clash of values, logical 
inconsistencies between two frameworks, or the presence of false or misleading facts'. Messy situations have the following features: the significance and reliability of information is problematical. There is no one significant and evident 'problem'; rather, different problems appear depending on the perspective taken. Different value orientations lead to political and emotional clashes among key players. Contradictions and paradoxes appear, as consequences are unknown. In order to cope with this situation, individuals rely on symbols and metaphors, rather than logical arguments, using their experience-based intuition.

\section{Interpreting and reflecting upon}

The interpretation and reflection of a specific situation brings two independent aspects. First, the way interpretation occurs affects its outcomes. Second, the results of interpretation and reflection of open-ended aspects, by definition, threaten existing work patterns, organizational structures and power positions. The latter activates covert political activity and unconscious defensive processes. In the former, interpretation and reflection is usually developed through schemata, cognitive maps and mental models. While those tools are important for dealing with uncertain and ambiguous situations,

there are problems inherent to the process of developing and using them. In the case of cognitive maps, for example, two problems have been pointed out (McCaskey, 1988:7). First, when available information is poor of insufficient, our minds reach beyond the evidence that can prove to infer what is going on. If concrete data does not exist, we invent beliefs about the truth of the matter, and then, especially in high stress situations, cling tightly to those beliefs. In these situations, the mind operates like an inference 
machine, combining the first wave of data with judgment to form educated guesses. Second, after the map is sketched, we tend to seal it off from disruptive changes. Then new information and frameworks are usually ignored, distorted and avoided in order not to challenge the core beliefs embodied in the established mental map.

\section{Clarifying preferences and problem-solving alternatives}

Clarifying preferences and developing problem-solving alternatives are two independent aspects. On the one side, the speed in which clarification of preferences occurs is a politically-related process. It depends on the time required to reach enough consensus and commitment to proceed to action. On the other side, the problem solving activity is 'soft' because of a combination of aspects that surround the process of problem formulation. Different types of problems lead to different way of formulating them; there are traps in the process of formulation of problems and metaphors used for problemsolving may also affect its outcome. These aspects are briefly reviewed next.

Different types of problems are formulated differently. Being aware of this fact is a 'soft' feature. Thomas (1988:58) has pointed out that two types of problems exist. In type I problems, because the problem is well defined, standard tools and methods are applied in order to solve it. In this case, it is not difficult to obtain acceptance of the solution by those responsible for implementing it, since both the problems and the solution are known. In type II problems, this refers to situations of high uncertainty and little information. In this case, internal political and bargain processes are important and acceptance of the solution is the most important evaluation of its quality. 
The single outcome solution trap in problem formulation. Problems have usually different, alternative solutions. For choosing the adequate solution for a specific situation, it is adequate to be aware of all relevant values and goals of the alternative proposed solutions. Nevertheless, some times decision-makers use the single outcome solution. That is, they focus on a single one of their goals or values and a single alternative course of action for achieving it. This means that they are implicitly rejecting other alternatives, and in justifying their choice, attempt to interpret facts in such a way that the favoured alternative appears to serve several values simultaneously and to have no costs associated with it. Furthermore,

'... they attempt to deny that there are tradeoffs and that there are some values which may not be served by their favoured alternatives. This is an extremely powerful simplification mechanisms and is more likely to be used in high complex and uncertain decision environments such as those characteristic of strategic planning. Since this mechanism allows decision-makers to deny the unpleasant value tradeoffs which are always present in a choice between alternatives, it significantly reduces the stress associated with ill-structured decision-making' (Thomas, 1988:60).

Finally, metaphors have a role in the problem-solving process. In uncertain and messy situations, rational, concrete, empirical arguments are short, or simply do not exist. The use of metaphors seems to be an adequate way to understand, order and make sense of a specific situation. Boland and Greenberg (1988) have called attention to the importance of being aware that different metaphors lead to different interpretations of the situation and therefore to the application of different problem-solving frameworks. 
"The results suggest that organic metaphors focus attention on the environment, growth and decentralized structures. Mechanistic metaphors on the other hand, focus attention on internal, centralized processes that carefully control the rate of change. Each metaphor highlights some features of the situation and hides others" (p.30)

\section{Gaining attention and agenda Building}

Agenda building is important because it represents the first step of the process of defining 'the problem' and its associated alternative solutions. Dutton (1988:131) has defined agenda building as the process through which strategic issues gain decisionmaker's attention and are legitimized in the organization. The agenda, therefore, is the product of forces of multiple levels of the organization that consciously or subconsciously work to make an issue consensual, legitimate and resource-consuming.

According to Dutton (1988), an issue gains relevance and interest via the blended effects of perceived attributes (issue salience) and the political foundation of an issue (issue sponsorship). Issue salience is related to issues of magnitude (the size of perceived impact on the organization's performance) and abstractedness (if the issue is highly abstract, gaining support for that issue would be difficult since they see the issue as irrelevant or unresolvable). Issue sponsorship, on the other hand, may play a crucial role in building an agenda, since sponsors mobilize interest and diffuse awareness about the issue. In uncertain and ambiguous situations, all those factors converge in order to facilitate - or block - issues on the agenda, the first step to define problems and 
associated solutions. Considering how salience issue and issue sponsorship interact, it is possible to enhance or diminish attention to a specific event.

Thus, agenda building constitutes a 'soft' issue because it provides the basis for understanding why different organizations respond differently to the same event. This understanding, in turn, may provide the basis for developing tactics that support agenda building.

\section{Gaining legitimacy and backing}

Despite the above processes being 'soft', and therefore occurring in the shadow or informal organization, once the solution has been reached, it is necessary to legitimise it with the formal organization in order to obtain allocation of resources and proceed with the experimentation phase. Gaining this support is a political process, which managers need to be aware of and know how to gain political support.

Incorporating outcomes in organizational memory

Organizational memory is a frame of reference in which managers interpret what they will do. Organizational memory is developed through sharing memories of what has worked and what has not worked in the past. Then, business 'recipes' are developed to help to interpret future actions. The problem is that new situations might demand totally new 'frameworks', since old recipes may become obsolete. Being aware of this is another 'soft' aspect that needs to be considered during the creation and transfer of organizational knowledge. For example, supporting 'deviant' behaviour in a highly 
hierarchical organization in order to promote the diffusion of knowledge helps the implementation of that behaviour.

\section{MANAGERIAL IMPLICATIONS OF THE ‘SOFT’ DIMENSION}

Guidelines for managerial action have been categorised in seven groups. In each group, key questions are formulated to aid practitioners make explicit, be aware and understand 'soft' issues. It should be noted that the importance of those managerial implications is a direct function of the degree the situation is open-ended, the external environment is uncertain/ambiguous, shared organizational goals are few and the extent to which organizational templates are highly abstract.

The micro-macro link:

- Which are the underlying reasons to transfer (either receiving or sending) an organizational concept?

- How do specific macro contextual factors affect personnel involved in terms of collaboration, motivation, trust and willingness?

- Who governs the OKT process?

- Which is the role of the receiving unit (in the sender-receiving unit)?

The 'content' of organizational knowledge:

- Is the concept being transferred of high or low abstraction level?

- Which are the main assumptions of the 'designers' of the organizational template regarding local conditions of operation? 
- To what extent does the implementation of the organizational concept demand trust, willingness and motivation from employees?

The 'process' of organizational knowledge:

- To what extent does the internal organization support trust, willingness and motivation from employees?

- To what extent can the implementation process of the organizational concept be planned or be emergent?

Detecting and selecting open-ended issues:

- Is the management prepared to use metaphors and symbols?

- How skilful are managers in using rhetoric?

Interpreting and reflecting upon:

- Is management aware of the trade-off between 'stability' of interpreted results versus updating and evolving the interpretation process?

- Is management applying an equilibrated approach in the stability versus evolution trade-offs of interpreted results?

- To what extent is the interpretation of the environment 'internally social constructed (or agreed)' or 'externally given'?

- Who governs the interpretation process?

- Who are the constituencies of the leading interpreting group/person? 
Clarifying preferences and problem-solving alternatives:

- Is the management aware of the single-outcome trap during the process of selecting problem-solving alternatives?

- Is the management aware of the key role played by applied metaphors?

- Is the management aware of pros and cons of using selected metaphors in the specific situation?

Gaining attention and agenda building:

- Is the management aware of the role of 'issue salience' and 'issue sponsorship' in the process of gaining attention and building agendas?

- Is the management prepared to manage 'issue salience' and 'issue sponsorship'?

\section{CONCLUSIONS}

Based on empirical work and a literature review, this paper has advanced a theoretical framework in order to aid both academics and practitioners to configure the different alternative theories and methods - which focus on the same problem from different levels of analysis - in order to 'make sense' of a specific context. The theoretical framework has three main dimensions: knowledge management, change management and a (focussed) "soft" dimension.

This paper has argued that the "soft" dimension helps to better understand the process of OKT. In this context, 'soft' issues refers to the mutual understanding - of both sender 
and receiver units - of underlying assumptions, the role of macro institutional factors affecting firm level actions (the macro-micro link) and interpretative aspects that permeate the process of organizational knowledge transfer, including knowledge management and change management issues.

After elaborating on specific key 'soft' issues emerging from open-ended situations, guidelines for managerial action were formulated in order to aid in making explicit, be aware and understand 'soft' issues embedded at both knowledge management and change levels.

The above guidelines represent an attempt to uncover the crucial 'soft' issues that are usually overlooked by the conventional literature. However, significant efforts are needed to map and understand the underlying 'logic' driving the dynamics of 'soft' issues. Whilst alternative approaches for coping with unstructured problems in ambiguous and dynamic contexts are emerging (c.f. Baumard, 2002; Kaltoft et.al., 2003; Augier et.al.,2001), still further theoretical and empirical work is necessary.

\section{References}

Argyris C. Schon D. (1974) Theory in practice, Jossey-Bass, San Francisco Augier M., Shariq J., Vendelo M. (2001) "Understanding contexts: Its emergence, transformation, and role in tacit knowledge sharing", Journal of Knowledge Management, Vol 5 No 2, pp. 125-137 
Baumard P. (2002) "Tacit knowledge in professional firms: The teachings of firms in very puzzling situations", Journal of Knowledge Management, Vol 2 No 2, pp. 135-152 Baumard P. (1999) Tacit Knowledge in Organizations, Sage, London

Beer M. and Nohria N. (2000) Breaking the Code of Change, Harvard Business School Press, Boston

Bessant J., Kaplinsky R., Lamming R. (2003) "Putting supply chain learning into practice“, International Journal of Operations \& Production Management, Vol.23, N.2, pp. 167-184.

Buchanan, D. and Badham, R. (1999), Power, Politics and Organisational Change, Sage, London.

Burkink T. (2002) "Cooperative and voluntary wholesale groups: channel coordination and interfirm knowledge", Supply Chain Management: An International Journal, Vol 7, No 2, pp. $60-70$

Burns T. and Stalker G.M. (1961) The Management of Innovation, Tavistok Publications, London

Boland R. and Greenberg R. (1988) "Metaphorical structuring of organizational ambiguity", In Pondy L.R., Boland R.J. and Thomas H. (Eds.) Managing ambiguity and change, John Wiley \& Sons, Chichester, pp. 17-36

Brown R. (1992) Understanding industrial organization, Routedge, London

Brown J. and Duguid P. (2001) "Structure and Spontaneity: Knowledge and Organization", In Managing Industrial knowledge, Nonaka I. and Teece D. (Eds.), Sage, Thousand Oaks 
Brown, J. and Duguid, P. (1998), "Organizing knowledge", California Management Review, Vol 40 (Spring), pp. 90-111.

Child J., Faulkner D. (1998) Strategies of Co-operation, Oxford University Press, Oxford Cohen W. and Levinthal D., (1990) "Absorptive capacity: A new perspective on learning and innovation", Administrative Science Quarterly, Vol 35, pp.128-152

Cohen M.D. (1991) "Individual learning and organizational routine - Emerging connections", Organization Science, Vol 2 No 1 pp. 135-140

Cohen M.D. and Bacdayan P. (1994) "Organizational routines are stored as procedural memory", Organization Science, Vol 5 No 4 pp. 554-569

Cole R. (1989) Strategies for Learning, University of California Press, Berkeley

Collins D. (1998) Organizational Change, Routledge, London

Clark P. (2003) Organizational Innovations, Sage, London

Clegg, S. and Palmer, G. (1996), "Introduction: Producing management knowledge", in Clegg, S. and Palmer, G. (Eds.), The Politics of Management Knowledge, Sage, London, pp.1-18.

Dutton J. (1988) "Understanding strategic agenda building and its implications for managing change", In Pondy L.R., Boland R.J. and Thomas H. (Eds.) Managing ambiguity and change, John Wiley \& Sons, Chichester, pp. 127-144

Easterby-Smith M., Burgoyne J., Araujo L. (2001) Organizational Learning and the Learning Organization, Sage, London

Easterby_Smith M. and Lyles M. (2003) "Re-reading organizational learning: selective memory, forgetting and adaptation", Academy of Management Executive, Vol 17 No 2, pp. 51-56 
Edmondson A. and Moingeon B. (1996) "When to learn how and When to learn why: Appropriate Organizational learning processes as a source of competitive advantage", In Moingeon B. and Edmondson A. (Eds.) Organizational Learning and Competitive Advantage, Sage, London, pp. 17-37

Fruin M. (1992) The Japanese Enterprise System, Claredon Press, Oxford Fruin M. (1997) Knowledge Works, Oxford University Press, New York Galbraith J. (2000) Designing the global corporation, Jossey-Bass, San Francisco Glisby M. and Holden N. (2003) "Contextual constrains in knowledge management theory: The cultural embeddedness of Nonaka's knowledge-creating company", knowledge and Process Management, Vol 10 No 1, pp. 29-36

Goh S. (2002) "Managing effective knowledge transfer: an integrative framework and some practice implications", Journal of Knowledge Management, Vol 6, No 2, pp.23-30 Guzman G. A. C. (2003) "Inside modular production networks: 'soft' operational issues in building factory competitiveness", Integrated Manufacturing Systems, Vol 14, No 1, pp. 6-15.

Guzman G.A.C., Wilson J. (2003) "Organisational Knowledge Transfer in Modular Production Networks: Experiences from Brazil', In Gregory M. and Shi Y. (Eds.) Exploiting the Potential of International Supply Networks, Published by Institute for Manufacturing, University of Cambridge, Cambridge, pp. 110-130.

Hendry, C. (1996), "Understanding and creating whole organizational change: Through learning theory", Human Relations, Vol 49 No 5, pp.621-41.

Kaltoft R., Boer H., Corso M., Gertsen F., Middel R., Nielsen J. (2003) "Factors affecting the development of collaborative improvement with strategic suppliers", In Spina G., 
Vinelly A., Cagliano R., Kalchschmidt, Romano P., Salvador F. (Eds.) One Word? One view of OM? EurOMA-POMS Conference, SGE Editoriali, Padova.

Kanter, R. (1996), "When a thousand flowers bloom: structural, collective, and social conditions for innovation in organizations", in Myers, P.S. (Ed.), Knowledge Management and Organisational Design, Butterworth-Heinemann, Boston, pp.93-131 Krebsbach-Gnath C. (2000) "Applying theory to organizational transformation", In Dierkes M., Antal A., Child J., Nonaka I. (Eds.) Handbook of Organizational Learning and Knowledge, Oxford University Press, London, pp. 886-891

Kotter J.P. (2000) Liderando mudancas, Campus, Rio de Janeiro

Krough G. von, Ichijo K., Nonaka I. (2000) Enabling Knowledge Creation, Oxford University Press, London

Lee, G. and Bennett, D. (2000), "Technological and organisational change in small to medium sized manufacturing companies - a learning organisation perspective", International Journal of Operations \& Production Management, Vol 20, No 5, pp. 549-72 Leonard-Barton, D.(1988) "Implementation as mutual adaptation of technology and organization", Research Policy, Vol 17, pp. 251-267

Leonard-Barton, D. (1995), Wellsprings of knowledge: Building and sustaining the sources of innovation, Harvard Business School Press, Boston.

Lillrank P. (1995) "The transfer of management innovations from Japan", Organizational Studies, Vol 16, No 6, pp. 971-990

Lullies, V. (2000), "Knowledge management is the key prerequisite for the improvement of new product and process development", in Jurgens, U. (Ed.), New Product Development and Production Networks, Springer-Verlag, Berlin, pp.322-36. 
Macharzina K., Oesterle M-J, Brodel D. (2000) "Learning in Multinationals", In Dierkes M., Antal A., Child J., Nonaka I. (Eds.) Handbook of Organizational Learning and Knowledge, Oxford University Press, London, pp. 631-656

March J.G. and Simon H.A. (1958) Organizations, Wiley, New York

McCalman J., Patton R., (1992) Change Management, Paul Chapman Publishing, London

McCaskey M.B.(1988) The challenge of managing ambiguity and change, In Pondy L.R., Boland R.J. and Thomas H. (Eds.) Managing ambiguity and change, John Wiley \& Sons, Chichester, pp. 1-15

Miles I. (1994) "Innovation in services”, In Dogson M., Rothwell R. (Eds.) The Handbook of Industrial Innovation, Edward Elgar, Cheltenham, pp. 243-256

Nelson R. (1993) (Ed.) National Innovation Systems: A comparative analysis, Oxford University Press, Oxford

Nonaka, I. and Takeuchi, H. (1995), The knowledge-Creating Company, Oxford University Press, New York.

Norman D. (1988) The Psychology of Everyday Things, Basic Books, New York Perrow, C. (1979), Complex Organisations: A Critical Essay, Scott Foresman, Glenview, ILL.

Scharman C.O. (2001) "Self-transcending knowledge: Sensing and organizing around emerging opportunities", Journal of knowledge Management, Vol 5 No 2, pp. 137-151 Senge P. (1990) The Fifth discipline, Doubleday, London 
Shariq S. (1999) "How does knowledge transform as it is transferred? Speculations on the possibility of a cognitive theory of knowledgescapes", Journal of Knowledge Management, Vol 3 No 4, pp. 243-251

Stacey R.D. (1996) Strategic Management and Organisational Dynamics, Pitman Publishing, London

Solvell O. and Zander I. (1999) "International diffusion of knowledge: isolating mechanism and the role of MNE", In Chandler A., Hagstrom P., Solvell O. (eds.) The dynamic firm, Oxford University Press, Oxford, pp. 402-416

Spender J.C. (1993) "Competitive advantage from tacit knowledge? Unpacking the concept and its strategic implications", Academy of Management Best paper Proceedings, pp. 37-41

Steenhuis H-J., Bruij E. (2001) "Tacit aspects of knowledge, information technology and the difficulties of information Exchange within manufacturing networks", The 6th International Symposium on International Manufacturing, 9-11 September, Cambridge University, Cambridge

Teece D. (2001) "Strategies for managing knowledge assets: The role of firm structure and industrial context”, In Managing Industrial knowledge, Nonaka I. and Teece D. (Eds.), Sage, Thousand Oaks, pp. 125-144

Thomas H. (1988) "Policy dialogue in strategic planning: Talking our way through ambiguity and change", In Pondy L.R., Boland R.J. and Thomas H. (Eds.) Managing ambiguity and change, John Wiley \& Sons, Chichester , pp. 51-77 
Tsang E. (1997) "Organizational learning and the learning organization: a dichotomy between descriptive and prescriptive research", Human Relations, Vol 50 No 1, pp. 7389.

Tsoukas H. and Vladimirou E. (2001) "What is organizational knowledge", Journal of Management Studies, Vol 38 No 7, pp. 973-993

Von Hippel E. (1988) The sources of innovation, Oxford University Press, New York

Westney D.E. (1987) Imitation and Innovation, Harvard University Press, Cambridge

Zahra S., George G. (2002) "Absorptive capacity: A review and reconceptualization, and extension", Academy of Management Review, Vol 27 No 2, pp. 185-203

\section{Autobiographical Note}

Gustavo A.C. Guzman is associate professor of Operations Management, Federal University of Minas Gerais, Brazil and Visiting Fellow, Nottingham University Business School. Email: gustavo.guzman@nottingham.ac.uk John F. Wilson is Director of the International Business History Institute, Nottingham University Business School

Email: j.wilson@nottingham.ac.uk 